\title{
ESCALA DE VALORACIÓN PARA LA REALIZACIÓN DE DEBATES EN SECUNDARIA
}

Scale of assessment of debates held in secondary school

Escala de classificação para a realização de debates no ensino secundário

Marta Montiel Nava (1)

Mirian Blanco de la Varga (2)

Ángel Pérez-Pueyo (3)

(1) IES Antonio García Bellido (Armunia, León), 646080010, marta.monnav@educa.jcyl.es

(2) IES Márques de Manzanedo (Santoña, Cantabria), 628650147, mblancod08@educantabria.es

(3) Universidad de León, 619867767, angel.perez.pueyo@unileon.es

\begin{abstract}
Resumen
Desde hace poco más de una década los docentes hemos de recoger en nuestras programaciones el trabajo y la evaluación competencial. Entre las muchas propuestas que se han presentado durante este período, hemos adaptado para nuestro trabajo diario en las aulas de secundaria algunos postulados del grupo Actitudes. La experiencia, que se ha desarrollado en distintos Institutos de Educación Secundaria (IES), recoge una propuesta de trabajo de las destrezas orales de expresión e interacción a través del aprendizaje cooperativo, algunos procesos de autorregulación y su evaluación a través de instrumentos que producen una evaluación formativa en la realización de debates en la etapa de Educación Secundaria Obligatoria (ESO). Además se presenta la última versión de la escala de valoración diseñada durante su puesta en práctica con distintos grupos.
\end{abstract}

Palabras clave: Competencias clave; evaluación formativa; escala de valoración; destrezas orales

\section{Abstract}


For a little more than a decade teachers have to include work and competency assessment in our programming. Among the many proposals that have been presented during this period, we have adapted for our daily work in the secondary classrooms some postulates of the group “Actitudes”. The experience, which has been developed in different secondary schools, involves a proposal of work on oral expression and interaction skills through cooperative learning, some self-regulation processes and their evaluation through instruments that produce a formative evaluation in the conduct of debates in the stage of compulsory secondary education. In addition, the latest version of the rating scale designed during its implementation with different groups is presented.

Keywords: Key competences; formative evaluation; rating scale; oral skills

\section{Resumo}

Há pouco mais de uma década que os Docentes têm de reunir nos seus horários Laborais a avaliação de competências. Entre as muitas propostas que foram apresentadas durante este período, adaptamos ao nosso trabalho em contexto de sala de aula, alguns princípios do grupo Actitudes. A experiência que foi desenvolvida nos diferentes Institutos Secundários engloba uma proposta de trabalho que inclui: A expressão de destreza oral e a sua interacção através da aprendizagem conjunta; alguns processos de auto-regulação e a sua evolução através de instrumentos que produzem uma avaliação formativa na realização de debates durante a Educação do Ensino Secundário. Além disso, é apresentada também a ultima versão de uma escala de classificação delineada para ser posta em prática com os diferentes grupos de trabalho.

Palavras-chave: competências-chave; avaliação formativa; escala de classificação; habilidades orais

\section{Introducción}

Desde que hace ya una década se introdujera en la normativa educativa española el concepto de competencia (Pérez-Pueyo, et al., 2013), primero básica y ahora clave, los docentes hemos llevado al aula su trabajo y evaluación en las materias de las que somos responsables. Esta labor no ha sido sencilla por dos razones: a) la falta de concreción administrativa al respecto y b) el abanico de propuestas que se han desarrollado en este 
período. En nuestro caso, la propuesta trazada desde el proyecto INCOBA (Pérez-Pueyo 2013) ha llenado el vacío ante el que nos encontrábamos a la hora de diseñar propuestas didácticas que respondieran a la normativa vigente. Además, dicha propuesta, se adapta a nuestros estilos de enseñanza.

Por otra parte, a pesar del avance en estos últimos años dentro del ámbito de la didáctica de la lengua (Ruiz, 2011), la enseñanza de las destrezas orales aún adolece de propuestas concretas que llevar al aula. En este caso se presenta una experiencia en la que se trabajan, en diferente grado, las destrezas orales (expresión, comprensión e interacción). Dicha propuesta se integra además en una experiencia que adapta mecanismos de autorregulación para enseñanza secundaria.

\section{Contextualización}

Esta experiencia se ha diseñado y desarrollado en distintos IES en los que hemos impartido docencia en la asignatura de Lengua Castellana y Literatura durante diferentes cursos y a distintos niveles. La escala de valoración se ha desarrollado e implementado en $1^{\circ}$ y $2^{\circ}$ y se está adaptando a $4^{\circ}$ de la ESO.

\section{Diseño y desarrollo}

Durante el primer trimestre se forman los grupos de aprendizaje cooperativo observando las relaciones que se dan en el grupo-clase para que los integrantes sean los adecuados y funcione la interdependencia positiva (Johnson \& Johnson, 1999). Además, se trabajan procesos de autorregulación (Casado, Pérez-Pueyo \& Casado, 2017) para lograr que el alumnado sea capaz de organizar el trabajo mediante el uso de planillas en las que figuran las tareas que deben realizar y el tiempo disponible. En relación a las destrezas orales, se trabaja para la realización de una exposición oral individual que se valorará mediante la rúbrica de evaluación de presentaciones orales para la ESO del grupo Actitudes (Pérez-Pueyo \& Sobejano, 2015).

En el segundo trimestre, al trabajar los contenidos relativos al texto argumentativo, se introduce el estudio del debate. Se proporcionan las instrucciones al alumnado para la preparación y desarrollo del mismo mediante un video-tutorial y se le distribuye la escala de valoración. Asimismo, se realizan distintas actividades para trabajar los conectores textuales, las fórmulas para pedir y dar la palabra y la cortesía comunicativa. Los alumnos deben organizar sus planillas de autorregulación para la 
preparación grupal buscando que todos los integrantes se documenten y planifiquen estrategias.

La evaluación formativa (López-Pastor, 2017) se incorpora en la realización de debates, a partir de la segunda mitad del segundo trimestre, ya que se tiene como referencia la escala de valoración diseñada para esta actividad (Tabla 1), se siguen las instrucciones dadas y se preparan los temas individualmente y con su grupo cooperativo.

Los temas son enunciados cerrados sobre los que todos los miembros del grupo tienen que documentarse y preparar argumentos a favor y en contra, ya que la postura a defender se conoce justo en el momento de la realización del debate. El proceso de documentación hace que los alumnos trabajen de forma cooperativa al tener que estar todos los miembros del grupo preparados para argumentar y defender distintas posturas.

El alumnado realiza autoevaluación y coevaluación con la escala de valoración de cada uno de los debates y esa evaluación se traduce en un porcentaje de la calificación final.

Tabla 1.

Escala de valoración debate

\begin{tabular}{|c|c|c|}
\hline \multirow{4}{*}{$\begin{array}{c}\text { Preparación } \\
\text { previa/conocimiento } \\
\text { del tema } \\
50\end{array}$} & La argumentación es sólida y sin lagunas. Denota preparación. & 50 \\
\hline & El discurso es coherente, pero hay ideas sueltas. & 25 \\
\hline & $\begin{array}{l}\text { Se hilvanan algunas ideas aunque no existe coherencia entre } \\
\text { ellas. }\end{array}$ & 15 \\
\hline & Hay una improvisación manifiesta al intentar argumentar/rebatir. & 5 \\
\hline \multirow{4}{*}{$\begin{array}{c}\text { Aportación personal al } \\
\text { desarrollo del debate } \\
20\end{array}$} & $\begin{array}{l}\text { Aporta argumentos interesantes contraargumentando a los } \\
\text { lanzados por sus compañeros }\end{array}$ & 20 \\
\hline & $\begin{array}{l}\text { Los argumentos aportados son interesantes para el desarrollo del } \\
\text { debate, pero no están organizados. }\end{array}$ & 15 \\
\hline & $\begin{array}{l}\text { Aporta argumentos sin relevancia para un desarrollo sólido de } \\
\text { las argumentaciones. }\end{array}$ & 10 \\
\hline & No contribuye al desarrollo del debate, lanza ideas sin pensar. & 5 \\
\hline \multirow{3}{*}{$\begin{array}{l}\text { Capacidad de } \\
\text { interacción } \\
20\end{array}$} & Contribuye en todo momento a la progresión del debate. & 20 \\
\hline & Esporádicamente realiza intervenciones adecuadas. & 10 \\
\hline & No es capaz de hilar/unir información. & 5 \\
\hline \multirow{4}{*}{$\begin{array}{l}\text { Puesta en escena } \\
10\end{array}$} & $\begin{array}{l}\text { Cumple con los cánones: uso de fórmulas, petición de palabra, } \\
\text { cierre de argumentación. }\end{array}$ & 10 \\
\hline & $\begin{array}{l}\text { Desarrolla el debate en calma y forma, pero no utiliza fórmulas } \\
\text { de cortesía o conectores adecuados. }\end{array}$ & 7,50 \\
\hline & Respeta, pero eleva la voz, pierde las formas. & 5 \\
\hline & No respeta las normas/ código establecido. & 2,50 \\
\hline
\end{tabular}

\section{Evaluación}


Contar con una escala de valoración como referencia ha enriquecido el proceso de enseñanza-aprendizaje. Por un lado, respecto al alumnado se evalúan aspectos como la labor previa de documentación, lo que ha mejorado su aprovechamiento del tiempo en clase y el rendimiento grupal. Asimismo, de forma individual, los alumnos han conocido el porqué de su nota, dándoles herramientas para mejorar sus aportaciones y que esto repercutiera positivamente en su calificación. Por otro lado, como docentes contamos con una herramienta que hace más tangible y objetiva la evaluación de la comunicación oral, puesto que la eficacia de la escala ha sido contrastada y mejorada con la práctica.

\section{Conclusiones}

A través de esta propuesta se puede contribuir a aspectos clave de la competencia en comunicación lingüística como son la expresión y la interacción oral. Debido a este carácter competencial, es fácilmente transferible a otras asignaturas que pueden hacer uso de ella para el trabajo de la expresión oral.

Las líneas futuras de desarrollo se dirigen a su adecuación y aplicación en otras etapas educativas, en la línea de lo que viene realizando el grupo Actitudes desde hace unos cursos con experiencias de este tipo conforme a su propuesta de secuenciación de competencias (Pérez-Pueyo, et al., 2015).

\section{Referencias}

Casado, O. M, Pérez-Pueyo, Á., \& Casado, P. (2017) La autorregulación en educación primaria una propuesta para favorecer la autonomía del alumnado. En Evaluación formativa y compartida en educación: experiencias de éxito en todas las etapas educativas (pp. 208-237) [documento de descarga] Recuperado en https://buleria.unileon.es/handle/10612/5999

Johnson, D. W., \& Johnson, R. T. (1999). Aprender juntos y solos. Aprendizaje cooperativo, competitivo e individualista. Buenos Aires: Aique.

López-Pastor, V. M., \& Pérez Pueyo, Á (Coords.) (2017). Evaluación formativa y compartida en educación: experiencias de éxito en todas las etapas educativas. León: Universidad de León [documento de descarga] Recuperado de https://buleria.unileon.es/handle/10612/5999 
Pérez-Pueyo, Á. (Coord.) (2013). Programar y evaluar competencias básicas en 15 pasos. Barcelona: Graó.

Pérez-Pueyo, Á., Heras, C., Barba, J. J., Casado, O. M., Vega, D., \& Pablos, L. (2013). Qué son las Competencias Básicas y cómo se trabajan en España. Diferentes maneras de llevarlas de la teoría al aula. Hacia el Proyecto INCOBA. León: Actitudes Profesionales S. L.

Pérez-Pueyo, Á., \& Sobejano, M. (2015) Recopilación de rúbricas para evaluar la expresión oral [documento de descarga] Recuperado de http://www.grupoactitudes.com/competencias-bsicas-nueva

Pérez-Pueyo, Á, Casado O. M., \& Sobejano, M. (2015). Propuesta de secuenciación de las competencias claves para Primaria y ESO [documento de descarga] Recuperado de http://www.grupoactitudes.com/competencias-bsicas-nueva

Ruiz, U. (Coord.) (2011). Didáctica de la lengua y la literatura. Barcelona: Graó. 